\title{
On being agents of change: A qualitative study of elective experiences of medical students at the Faculty of Health Sciences, University of Cape Town, South Africa
}

J Irlam, ${ }^{1}$ BSc, BSc (Med) Hons, MPhil (Epidemiology); L Pienaar, ${ }^{2}$ BSc (Physio), MSc (Physio); S Reid, ${ }^{1}$ BSc (Med), MB ChB, MFamMed, PhD

${ }^{1}$ Primary Health Care Directorate, Faculty of Health Sciences, University of Cape Town, South Africa

${ }^{2}$ Health Education Development Unit, Faculty of Health Sciences, University of Cape Town, South Africa

Corresponding author: J Irlam (james.irlam@uct.ac.za)

Background. Student electives during the 5th year of the University of Cape Town (UCT) medical curriculum provide a 4-week work experience in the health system. The reflective reports of past students indicate that the electives may significantly shape their developing identities as health professionals and agents of change.

Objective. To better understand how 5th-year medical elective students perceive themselves as agents of change to strengthen the elective programme in the Faculty of Health Sciences, UCT. The hypothesis was that the more choice that students are given over their learning, the greater is their sense of agency. Methods. Thirteen 5th-year student volunteers participated in four focus group discussions soon after completing their electives in district, regional or tertiary health facilities in the South African health system. Thematic analysis of the transcripts was performed independently by two of the authors. Results. Key themes were the importance of providing holistic patient-centred care, becoming a competent health professional, working within the health team and advocating for a better health system. The elective experience helped students to be more confident in their abilities and to better understand how to effect change at a clinical and health system level.

Conclusion. This study supported the hypothesis that the more choice students have over their learning, the greater is their sense of agency. The electives are appreciated as opportunities to develop clinical skills and competencies and to better understand the role of future doctors within the health team and health system. The value of the UCT elective programme could be enhanced by greater promotion, funding for rural electives, and post-elective peer-topeer feedback sessions. This study will inform planning for an extended 2016 medical elective programme in the Faculty.

Afr J Health Professions Educ 2016;8(1):41-44. DOI:10.7196/AJHPE.2016.v8i1.540

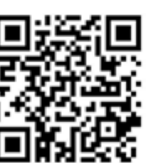

In the 21 st century, health science faculties need to be more than institutions of education where health science students develop the knowledge, skills and competencies for becoming health professionals. It is essential that students are equipped to meet global health challenges and that their skills are relevant to the needs of local communities. ${ }^{[1,2]}$ This means working with communities to improve their health and access to health services, especially communities that struggle for health against multiple social and economic barriers. ${ }^{[3]}$ In South Africa (SA), poor rural communities have least access to healthcare. ${ }^{[4]}$

Doctors are considered the 'attorneys of the poor', an advocacy role that requires a strong sense of social responsibility in medical education and practice. According to Dharamsi et al. ${ }^{[5]}$ developing and nurturing a moral sense of responsibility depends largely on the curriculum and the pedagogical approaches adopted by an institution. In striving to entrench these values of social accountability, medical schools should engage with national and regional stakeholders, such as medical educators, health managers, doctors, communities and policy makers. ${ }^{[6]}$ This engagement should inform the educational model, research agenda and health services offered by medical schools in order to align medical education with local health needs. Woollard and Boelen ${ }^{[6]}$ assert that 'the medical school must provide ample and appropriate learning opportunities for medical students to grasp the complexity of socioeconomic determinants in health. It must explicitly adopt a preferential model of practice that integrates the biomedical aspects of diseases into a holistic approach to health and wellbeing, and it must offer role models to reinforce this approach'
Developing future medical doctors to be advocates for greater health equity and quality patient care may require health science faculties to re-orientate their educational activities and contexts of learning. Traditional curricula have not kept pace with rising inequities in health and emerging health risks and continue to graduate students who lack the competencies to address these challenges. ${ }^{[7]}$ It is therefore essential that medical students learn and practise in settings that provide authentic community exposure, to develop their capacity for social change. ${ }^{[8,9]}$ We define this capacity in terms of transformative education of students as agents of change towards better patient care and greater health equity. Student electives can contribute to the development of social conscience and the knowledge, skills and attitudes needed for addressing the health needs of diverse communities. ${ }^{[10]}$ Elective students may have opportunities for deeper engagement with community and social structures that allow application of their altruistic ideals. ${ }^{[1]} \mathrm{We}$ therefore hypothesised that the more choice that students are given over their learning, the greater is their development of a sense of agency.

The Faculty of Health Sciences, University of Cape Town (UCT) aspires to promote quality patient care and social justice within the lead theme of the equitydriven primary healthcare (PHC) approach. ${ }^{[12]}$ The 5th-year medical elective, introduced in its present form into the curriculum in 2006, is an opportunity for students to work for 4 weeks in the health system to develop their clinical skills and better understand the principles of the PHC approach. The vast majority of students choose clinical electives in general medical practices, community health centres or hospitals in the SA public sector. A minority work in the for-profit and not-for-profit private sector and a handful undertake research electives. 
The electives are assessed based on a written reflective report by the student, accompanied by a brief evaluation from the elective supervisor on site. Students' clinical elective reports over the past 9 years indicate that the electives raise their awareness of the social determinants of health and may significantly shape their developing identities as health professionals with agency.

The purpose of this study is to better understand how 5th-year medical elective students perceive themselves as agents of change, to strengthen the elective programme in the Faculty of Health Sciences, UCT.

\section{Methods}

Fifth-year medical students in four elective rotations of the class of 2014 (76 students of a class total of 184) were invited to participate in the study within 2 months of completing their electives. Only those who had completed their electives in district (primary-level care), regional or tertiary health facilities in the SA health system were eligible for inclusion. All those who accepted the invitation were included in the study.

One of the authors (LP) facilitated four focus group discussions (FGDs) in a private venue in the Faculty of Health Sciences, UCT. Five questions (Table 1) were discussed, which were drafted by JI, based on review of past elective reports. The questions were refined in consultation with colleagues, three of whom teach on the Faculty's medical programme and two on the allied health sciences programme. The questions were pretested by LP on three students, who were also participants in the study, and were well understood.

The FGDs were recorded by LP and transcribed by a professional transcription agency. JI and LP analysed the transcripts independently without use of a software package and then discussed their analyses to reach consensus on the key themes.

Ethical approval for the study was obtained from the Human Research Ethics Committee (HREC \#133/2014) of the Faculty. The UCT Department of Student Affairs gave permission for student participation and participants signed a standard consent form.

Table 1. Focus group discussion questions

1. Please share what you learnt from your elective about being an agent of change as a student doctor. Provide some examples.

2. Please tell me how you think you can be an agent of change as a future doctor in the SA healthcare setting.

3. How do you think the elective programme could better prepare you to be an agent of change in the SA healthcare setting?

4. How do you think the Faculty could better prepare you to be an agent of change in the SA healthcare setting?

5. What does being an 'agent of change' mean to you?

\section{Results}

Thirteen medical elective students (10 females and 3 males) participated in one of four FGDs with their elective peers, averaging three students per FGD. The following key themes arising from the discussions are described: the importance of providing holistic patient-centred care, becoming a competent health professional, working within the health team and advocating for a better health system.

\section{Providing holistic patient-centred care}

The PHC approach emphasises the principle of holistic patient-centred care, which includes biopsychosocial assessments of patients, good communication, effective health promotion, and involvement of families and communities in care. Participants reflected on the multiple aspects of this principle and how it strengthens the agency of health professionals in the lives of their patients.

The relationships of health professionals with their patients are strengthened by demonstrating concern for the whole person:

'The [general practitioner] GP was able to actually diagnose and treat the person fully and at the same time he had such a good relationship with his patients because he is their family doctor and he treated their mothers, their grandfathers and their great grandmother ... and that connection that you have with your patient is so much better'. (FGD, 21 May)

Speaking the language of one's patient enhances the patient encounter and promotes their health more effectively:

'I just like the fact that we get taught ... different languages during our studies. I realised how important it is ... I don't think I maximise my exposure to the language to the best of my ability, and I think that one thing I would change personally is to be able to speak the language of the people that I'm going to be treating.' (FGD, 2 June)

Being a good listener demonstrates humility and empathy towards your patients:

'... just being kind and listening to people and ... getting yourself out of this role and off this pedestal that you're sitting on and just being human and approaching people on that level.' (FGD, 31 July)

Making time to counsel and educate patients about their health is important for early prevention of disease:

'It made me feel like the simplest things could actually make a difference because I think the way lifestyle conditions have taken over, that our focus shouldn't be more on treating complications; you should go a few steps back and prevent them from happening in the first place.' (FGD, 31 July)

Respecting your patient and the importance of each consultation makes a real difference in their lives:

'I think it's about taking responsibility for what you know, and taking responsibility for what you're learning and making a difference in patient's lives ... That patient made an effort to see you, you should make an equal effort to treat them well and not just see them as like, "oh number three, number four, number five". Realise the importance of each patient encounter.' (FGD, 31 July)

\section{Becoming a competent health professional}

The UCT electives are seen as a valuable opportunity to develop clinical skills and competencies and to address one's deficiencies. Having extended responsibilities for patient care develops greater self-confidence and deeper insight into what it means to be an agent of change, but it can also erode one's empathy:

'As agents of change, you always need to come back to the reason why you made the decision in the first place. And so when I came into med-school, I think I was possibly a lot more understanding and empathic than I am now.' (FGD, 2 June) 
An agent of change is someone who is able to identify problems and find feasible solutions:

'So it's someone who is able to identify problems, but also to identify realistic solutions and be able to come up with ways in which to implement those solutions; and more than that it's someone that is able to network.' (FGD, 4 June)

Initiating change requires sharing your ideas and convincing others to participate in what can be a long process:

'Yes, so that excitement again made me realise that you can't sit back and watch things happen around you. If you identify a problem, take it upon yourself to either speak to other people who can do something about it, or start the process yourself. Initiate change because that's why you studied medicine, to help people and you have the ability to start the process and get everybody involved.' (FGD, 31 July)

'... having perseverance and dedication to whatever goals you have, as change usually takes a long time; ... to make the changes you need to convince the rest of the team; ... to almost prove it, sell your idea, why this needs to happen.' (FGD, 4 June)

Having greater clinical responsibility is very motivating for most students and develops a deeper appreciation of what they are able to do in the 'real world' of medicine:

'Because I have been in a more practical setting where I was kind of given responsibilities, it makes me appreciate more what I learn now.' (FGD, 31 July)

'I feel like studying for 6 years, we kind of lose the reason we signed up for medicine, like it's just, it's not really what we thought it was, and then getting this four weeks was a little taste of what life will be like, and that just gives you that light push until the end.' (FGD, 31 July)

The elective is a time for reflection on the medical profession and one's personal learning experiences and objectives:

'I'm starting to think more consciously about my profession, like medicine is so broad, there's so much to know, there's so much to learn. (FGD, 31 July)

'I only have a year and a half left of purely academic undergraduate time, and I need to make sure that I use it wisely. I want to be able to make sure that I know what I am doing, and I can manage, especially in emergency situations, until someone more senior can get there.' (FGD, 4 June)

'It's just finding that niche and I think the elective helped us realise a little bit more what path we will be going on, and knowing where we will be going.' (FGD, 31 July)

\section{Working in the health team}

After years of being junior members of the health teams in large training hospitals, the elective experience of being respected as equals within the health team is very empowering. Respect for each other's roles builds the confidence of the team, as observed by one student in a rural district hospital:

'I also think that the sisters there had confidence in their position, they wouldn't feel like the doctors are looking down on them, or feeling like they are superior; and with everybody understanding that everyone has a different role, you are all contributing very much to the team.' (FGD, 4 June)

A well-functioning health team is essential to improving healthcare and motivating health workers:

'It's helpful for the patient if I work well with the team, with the nurses ... if you have a good relationship, then our patients tend to get better care.' (FGD, 4 June)

'And the way that they used the multidisciplinary team in psych it's so interesting ... everyone was just discussing how we can make his life better, you know. So if you work like that, eventually everyone will be motivated.' (FGD, 2 June)

Rural electives expose students to another important principle of the PHC approach, which is collaboration between the hospital-based health team and its community partners. The partnership with a non-profit organisation called Mentor Mothers to improve neonatal care in a rural district was cited as a good example:

'The mentor mother will come to the mother's home, in the middle of the rural community and speak to her, and follow her up, and refer her back to the hospital if there are any problems that the doctors can sort out, or refer them to [occupational therapy] OT if that is needed. And so it's doing things like that that really require lateral thinking, that really can make a big difference, and it's not an extra burden on the hospital at all; in fact it's really helpful because it means you're not admitting 6-week-old babies that are already malnourished.' (FGD, 4 June)

\section{Advocating for a better health system}

Several students felt that their elective experiences helped them to realise the important social determinants of health, to see what may be needed to improve healthcare in the local setting, and to understand how they can advocate for a better health system.

Careful observation to identify deficiencies in the healthcare setting is seen as an essential first step:

'... seeing things that hadn't yet been changed, or seeing difficulties to implement change, I think part of being a student then was bringing up like why ... just asking why this is not yet done, and having discussions with the doctors there, which was then finding out difficulties that they're facing.' (FGD, 4 June)

'... it's so easy for us to judge what's right or wrong, but the truth is we're a new set of eyes and we should be the driving force.' (FGD, 2 June)

Although the shortage of resources is a common complaint, minimising wastage should be everyone's responsibility:

'So I think if you just stop wasting some of our resources and making sure that like you know whatever is done with this patient, because we're so resource limited, it's actually needed for that patient'. (FGD, 2 June)

One student saw the maldistribution of specialists and the poor living conditions of doctors in many rural areas as important challenges for the SA health system:

'We need to evaluate how we distribute our specialists, but more than that, we need to look at the living conditions of doctors in rural areas, 
because it's natural for a doctor not to want to go and live somewhere where he can't send his or her kids to school or where there isn't a proper house, or there isn't running water, and it is unfair to send doctors to places like that, if they don't want to go. So we really need to look at why certain provinces are better than others, and we need to look at fixing that.' (FGD, 4 June)

The challenges of the health system have implications for the type of doctors that should be trained and for where they are trained:

'The doctors that we need ... are actually okay to go and work in a rural area where you don't have proper referral systems, and the [antiretrovirals] ARVs are out of stock occasionally, and where you really have to make a plan.' (FGD, 4 June)

Working to change the system can seem overwhelming; some students would rather focus on doing what they can at the individual level:

'I think it's absolutely overwhelming, and if you're that person where you are motivated to make change on a big level, then you have to step out of the hospital to do it. But I think for me that just loves patient contact, I'm going to do what I can for this patient, just this one particular patient. So mine is a personal agent of change.' (FGD, 2 June)

Working together makes one a more effective agent of change at a health systems level:

'One person can't change the whole system nationally; we need to all work together and ... fill in the gaps that you can.' (FGD, 4 June)

\section{Discussion}

In this study, we sought to understand medical elective students' perceptions of themselves as agents of change during their 5th-year electives. We found that the electives are generally perceived as good opportunities to practise holistic patient-centred care, to develop clinical skills and competencies, to work within the health team, to gain first-hand awareness of the determinants of health, and to better understand the role of future doctors within the health system.

Our findings support the hypothesis that the more choice students have over their learning within the curriculum, the more opportunity they have to develop agency or self-efficacy. ${ }^{[13]}$ This may contribute to a stronger internal locus of control that may result in greater agency and impact as graduate doctors. ${ }^{[14]}$ These findings are consistent with the findings of Dharamsi et al. ${ }^{[15]}$ that students became more aware and engaged with the needs of vulnerable communities during international service-learning programmes. Smith and Weaver ${ }^{[16]}$ found that students became more aware of primary care and public health issues while undertaking their electives.

Our study participants recommended that the Faculty promote the electives more (an extended pre-elective session on the range of elective opportunities was suggested), restore the funding for rural electives (discontinued due to budget constraints), and introduce post-elective peer-to-peer feedback sessions. Post-elective workshops with faculty staff and student peers have enhanced the educational value of student electives at Newcastle University, UK, and would be feasible within the Faculty. ${ }^{[17]}$ Offering training opportunities beyond relatively well-resourced teaching hospitals and health centres was seen as essential for ensuring that UCT medical graduates are equipped to practise in an under-resourced health system such as that in SA.

A limitation of this study is the small group of volunteer participants, whose perceptions about the electives may be more positive than those of their non-participating peers. Nevertheless, our findings on the value of the electives are consistent with the vast majority of elective reports assessed by JI since the inception of the elective programme in 2006.

We conclude that the UCT medical elective programme makes a valuable contribution to the development of agency among students. This study provides timely and relevant evidence for an extended 2016 medical elective programme at UCT and indicates the value of health science electives in other faculties.

Declaration of funding. We received support from the UCT Internal Research Award.

Acknowledgements. We thank our colleagues, C S Naidu, H Talberg, M Setshedi and S Amosun, for their assistance in developing the protocol, the 5thyear UCT students for their participation in the focus group discussions, Ms Elloise Kennell for administrative support, and On Time Transcribers for the FGD transcriptions.

\section{References}

1. McMenamin R, McGrath M, Cantillon P, MacFarlane A. Training socially responsive health care graduates: Is service learning an effective educational approach? Med Teach 2014;36(4):291-307. [http://dx.doi.org/10.3109/ 0142159X.2013.873118

2. World Health Organization (WHO). WHO transformative scale up of health professional education. An effort to increase the numbers of health professionals and to strengthen their impact on population health. Geneva: World Health Organization, 2011. http://whqlibdoc.who.int/hq/2011/WHO_HSS_HRH_HEP2011.01_eng.pd (accessed 16 October 2014).

3. Coria A, McKelvey TG, Charlton P, Woodworth M, Lahey T. The design of a medical school social justice curriculum. Acad Med 2013;88(10):1442-1449. [http://dx.doi.org/10.1097/ACM.0b013e3182a325be]

4. Harris B, Goudge J, Ataguba JE, et al. Inequities in access to health care in South Africa. J Public Health Policy 2011;32(Suppl 1):S102-S123. [http://dx.doi.org/10.1057/jphp.2011.35]

5. Dharamsi S, Ho A, Spadafora SM, Woollard R. The physician as health advocate: Translating the quest for social responsibility into medical education and practice. Acad Med 2011;86(9):1108-1113. [http://dx.doi.org/10.1097/ acm.0b013e318226b43b]

6. Woollard B, Boelen C. Seeking impact of medical schools on health: Meeting the challenges of social accountability. Med Educ 2012;46(1):21-27. [http://dx.doi.org/10.1111/j.1365-2923.2011.04081.x]

7. Frenk J, Chen L, Bhutta Z, et al. Health professionals for a new century: Transforming education to strengthen health systems in an interdependent world. Lancet 2010;376(9756):1923-1958. [http://dx.doi.org/10.1016/

8. Papadimos TJ, Murray SJ. Foucault's 'fearless speech' and the transformation and mentoring of medical students. Philos Ethics Humanit Med 2008;17(3):12. [http://dx.doi.org/10.1186/1747-5341-3-12]

9. Elam CL, Sauer MJ, Stratton TD, Skelton J, Crocker D, Musick DW. Service learning in the medical curriculum Developing and evaluating an elective experience. Teach Learn Med 2003;15(3):194-203. [http://dx.doi org/10.1207/S15328015TLM1503_08]

10. Murray RB, Larkins S, Russell H, Ewen S, Prideaux D. Medical schools as agents of change: Socially accountable medical education. Med J Aust 2012;196(10):653. [http://dx.doi.org/10.5694/mja11.11473]

11. Meili R, Fuller D, Lydiate J. Teaching social accountability by making the links: Qualitative evaluation of student experiences in a service-learning project. Med Teach 2011:33(8):659-666. [http://dx.doi.org/10.3109/01421 9X.2010.530308]

12. UCT Faculty of Health Sciences. Vision, Mission, Values and Goals. http://www.health.uct.ac.za/about/mission/ (accessed 18 February 2014).

3. Bandura A. Self-efficacy: The Exercise of Control. New York: Freeman, 1997:604.

14. Rotter JB. Generalized expectancies for internal versus external control of reinforcement. Psychol Monogr Rotter JB. Gener.
1966;80(1): $1-28$.

15. Dharamsi S, Richards M, Louie D, et al. Enhancing medical students' conceptions of the CanMEDS health advocate role through international service-learning and critical reflection: A phenomenological study. Med Teach 2010;32(12):977-982. [http://dx.doi.org/10.3109/01421590903394579]

16. Smith JK, Weaver DB. Capturing medical students' idealism. Ann Fam Med 2006;(Suppl 1):S32-S37;S58-S60 [http://dx.doi.org/10.1370/afm.543]

17. Evans R, Dotchin C, Walker R. Maximising the value from the elective experience: Post-elective workshops. Clin Teach 2013;10(6):362-367. [http://dx.doi.org/10.1111/tct.12033] 